\title{
Intestinal parasites among migrant barn swallows (Hirundo rustica) in the central region of Mazandaran Province, Northern Iran
}

\author{
Mahdi Fakhar ${ }^{1}$, Tooran Nayeri Chegeni ${ }^{2}$, Reza Bastani ${ }^{1}$, Zahra Hosseininejad ${ }^{2}$, Reza Saberi and Saber Armat ${ }^{2}$ \\ 1. Molecular and Cell Biology Research Center, Department of Parasitology, Faculty of Medicine, Mazandaran University \\ of Medical Sciences, Sari, Iran; 2. Student Research Committee, Department of Parasitology, Faculty of Medicine, \\ Mazandaran University of Medical Sciences, Sari, Iran. \\ Corresponding author: Mahdi Fakhar, e-mail: mahdif53@yahoo.com \\ Co-authors: TNC: tooran.nayeri@gmail.com, RB: rbastani41@gmail.com, ZH: hoseini125@yahoo.com, \\ RS: reza.sab.68@gmail.com, SA: saber_armat@yahoo.com \\ Received: 25-02-2018, Accepted: 13-07-2018, Published online: 28-08-2018
}

doi: 10.14202/vetworld.2018.1179-1182 How to cite this article: Fakhar M, Chegeni TN, Bastani R, Hosseininejad Z, Saberi R, Armat S (2018) Intestinal parasites among migrant barn swallows (Hirundo rustica) in the central region of Mazandaran Province, Northern Iran, Veterinary World, 11(8):1179-1182.

\begin{abstract}
Aim: Swallows are a family of migratory birds found worldwide except Antarctica. Annually, a number of species of swallows migrate to Iran. As they make their nests close to human living places, this may be a potential risk for public health. Conversely, no study has been conducted on intestinal parasitic infections of these birds so far. Therefore, the objective of this study was to determine the prevalence of intestinal parasites in migratory swallows (Hirundo rustica) in the central region of Mazandaran Province, Northern Iran.
\end{abstract}

Materials and Methods: In this cross-sectional study, 205 feces samples from two districts (Sari and Qaemshahr) in the central region of Mazandaran were randomly collected during the summer and spring sessions of 2016-2017. The collected samples were examined using the routine direct fecal examination and formalin-ethyl acetate concentration. In addition, the samples were examined by cold acid-fast staining method to detect possible Cryptosporidium oocysts.

Results: The results of this study indicated that 38 samples (18.5\%) were infected with intestinal parasites. Among the helminthic parasites, eight genera and species were identified as follows: Ascaridia galli, Syngamus trachea, Raillietina, Toxocara spp., Choanotaenia, Taenia spp., Ascaridia spp., and Moniezia spp. In addition, among protozoan parasites, only the Coccidia spp. oocysts were identified.

Conclusion: Our findings showed a relatively high prevalence of parasitic infections in migratory barn swallows in Mazandaran Province. Given the presence of zoonotic parasites in the samples, further investigations are needed to identify all parasites fauna, particularly zoonotic species among swallows in the region.

Keywords: barn swallow, Hirundo rustica, intestinal parasites, Iran, zoonosis.

\section{Introduction}

Swallows are a family of passerine birds (Hirundinidae family) found around the world. There are around 83 species and 19 genera [1]. These migratory birds are found around the world on all continents except Antarctica. The barn swallow, Hirundo rustica, is the most widespread species of swallow in the world. There are six subspecies of $H$. rustica, which breed across the Northern Hemisphere. Of these species, four are migratory birds among which $H$. rustica migrates to Northern Iran in spring. These birds can live in different geographic locations. However, these birds feed on insects; they often live in places where insects are abundantly found [1-3].

Swallows are closely related to people's lives in both urban and rural residential houses. Swallows

\footnotetext{
Copyright: Fakhar, et al. Open Access. This article is distributed under the terms of the Creative Commons Attribution 4.0 International License (http://creativecommons.org/licenses/by/4.0/), which permits unrestricted use, distribution, and reproduction in any medium, provided you give appropriate credit to the original author(s) and the source, provide a link to the Creative Commons license, and indicate if changes were made. The Creative Commons Public Domain Dedication waiver (http://creativecommons.org/ publicdomain/zero/1.0/) applies to the data made available in this article, unless otherwise stated.
}

can easily nest in residential places, and most of them return to their nests each year and they may prefer to choose the same nest $[2,4]$. According to the annual censuses, about 2 million migratory birds come to Iranian seashores and wetlands every year. On the other hand, studies have shown that birds can transmit a variety of potential pathogens to pets and humans including Cryptosporidium, Capillaria, Heterakis gallinarum, Syngamus, and Cryptococcus [5-8].

Common zoonotic parasitic diseases are one of the major health, economic, and social problems in many developing countries including Iran. The transition of these diseases to humans is an important issue in terms of health and veterinary medicine, especially for the health-care system in providing services and against common infectious diseases. Our previous study in Mazandaran Province (area of the present study) showed that excreta of swallow harbor various species of yeasts, mainly Cryptococcus neoformans [9].

Our literature review showed that no study has been conducted on the prevalence of intestinal parasitic infections of these birds in the world as well as Iran. Therefore, the present study was conducted with 
the aim of investigating the parasitic fauna and assessing its potential in infecting the peripheral environment in Mazandaran Province.

\section{Materials and Methods}

Ethical approval

During all stages of our research, all applicable international, national, and/or institutional guidelines for the care and use of animals were followed. The fecal samples were collected according to the ethical approval of the Student Research Committee at Mazandaran University of Medical Sciences.

\section{Study area}

Throughout the summer and spring sessions of 2016-2017, the present study was carried out in two districts, Sari (as capital of Mazandaran Province) and Qaemshahr (as one of the main cities) in the central region of Mazandaran Province $\left(53^{\circ} 6^{\prime} \mathrm{E}, 36^{\circ} 23^{\prime} \mathrm{N}\right)$, Northern Iran. This province has a humid and temperate weather conditions with an average yearly rainfall of about 1000-1200 mm [10].

\section{Sample collection}

To investigate intestinal parasite infection in swallows of Sari and Qaemshahr, 205 samples were collected by cluster sampling. The samples were randomly collected from different regions of these two cities (streets, residential houses, hospitals, and public places). The date of sampling and related address was written on each container for any probable resampling purpose. For sampling, the nests of the swallows in different areas of the cities were identified, and the feces were collected right from their nests. Immediately after collection, the feces samples were transferred to the parasitology laboratory of Mazandaran University of Medical Sciences.

\section{Sample examination and identification}

All samples were first examined by routine direct fecal examination method. Then, formalin-ethyl acetate technique using Parasite test kit (Paramed, Iran) was used to detect possible parasite eggs and cysts as follows: The two matching parts of the test tube were unscrewed, and the cylindrical part was placed inside the tube. Then, $3.5 \mathrm{~mL}$ of $10 \%$ formalin-saline and ethyl-acetate working solution was added, and some feces (about $1 \mathrm{G}$ ) were taken by abaisse-langue and added to the solution. The tube was well vortexed for $30 \mathrm{~s}$, in a way that the cone section was upright. In the next step, the parasite test was reversed and centrifuged at $400 \mathrm{~g}$ for $3 \mathrm{~min}$. After centrifugation, the tube was abruptly opened, and the solution in a cylindrical part was discarded. Then, the remaining fluid in the conical portion was taken, the upper part was slightly removed, the residual was mixed. At the final stage, a drop of sediment was placed on the slide and examined under the microscope in terms of parasite eggs and cysts. In addition, to investigate the presence of Cryptosporidium spp., in the samples taken from the swallows, cold acid-fast staining method was used [11]. Finally, morphological characteristics were used for every specimen to detect the identified parasites based on identification key [12]. Our study was a descriptive cross-sectional study; hence, a negative control was not included in the study.

\section{Results}

In this study, 205 samples of swallow feces were examined for parasitic infections, of which 38 samples $(38 / 205,18.5 \%)$ were positive. The worm infections belong to eight species and genera, including Ascaridia gall, Toxocara spp., Taenia spp., Syngamus trachea, Raillietina spp., Moniezia spp., Ascaridia spp., and Choanotaenia spp. Furthermore, among protozoan infections, Coccidia oocytes were the only infection detected (Figure-1). The highest prevalence in the infected swallows was related to A. galli (20/38, 52.3\%) and then Taenia spp. (6/38, 15.8\%) (Table-1). Furthermore, no trematode was found in the samples examined. It should also be noted that no cases of Cryptosporidium infection were detected in this study. Meanwhile, of the total of 38 positive specimens, $22(57.9 \%)$ belonged to Qaemshahr and $16(42.1 \%)$ to Sari districts.

\section{Discussion}

The results of our preliminary study indicate a relatively high prevalence (18.5\%) of parasitic infections among migratory swallows of Mazandaran Province. The highest infection rates were related to A. galli, Taenia spp., and Toxocara spp. with $52.3 \%$, $15.8 \%$, and $13.1 \%$, respectively. As it was mentioned, no study has investigated the parasitic infection of migratory swallows in Iran; though, several studies have been conducted on hemoparasites such as Plasmodium spp., and ectoparasites of these birds in other regions of the world [13]. The high infection rate of $A$. galli in our study is almost similar to the results of Eslami et al. [14] that reported a high prevalence (56\%) of A. galli among native free-range fowls in the Golestan Province, Northern Iran. They also reported other species of parasites which detected in alimentary canals of these birds as follows: H. gallinarum (24\%), Capillaria anatis (4\%), Cheilospirura hamulosa

Table-1: Prevalence of intestinal parasites in feces of migratory swallows according to parasite species and place in Mazandaran Province.

\begin{tabular}{llc}
\hline Parasite species & City & $\begin{array}{c}\text { Number of } \\
\text { positive (\%) }\end{array}$ \\
\hline Ascaridia galli & Qaemshahr & $20(52.3)$ \\
Taenia spp. & Sari & $6(15.8)$ \\
Toxocara spp. & Sari & $5(13.1)$ \\
Syngamus trachea & Sari & $2(5.3)$ \\
Raillietina spp. & Sari & $1(2.7)$ \\
Moniezia spp. & Sari & $1(2.7)$ \\
Choanotaenia spp. & Sari & $1(2.7)$ \\
Ascaridia spp. & Qaemshahr & $1(2.7)$ \\
Coccidia spp. oocyst & Qaemshahr & $1(2.7)$ \\
Total & & $38(18.5)$ \\
\hline
\end{tabular}




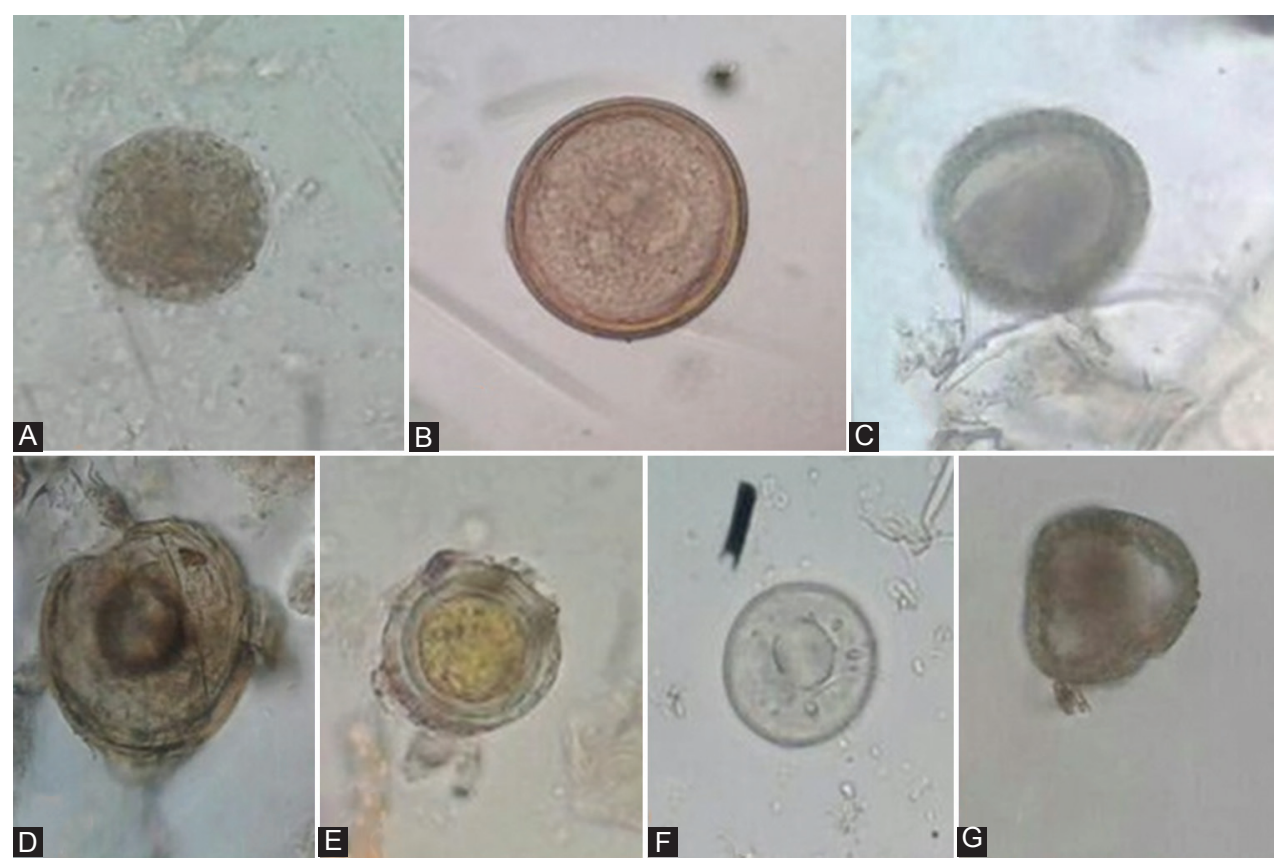

Figure-1: Images showing intestinal parasites identified in immigrant barn swallows feces in Mazandaran Province (40x). (a) Ascaridia galli, (b) Taenia spp., (c) Toxocara spp. egg, (d) Raillietina spp., (e) Choanotaenia spp., (f) Coccidia oocyst, (g) Moniezia spp.

(4\%), Raillietina tetragona (58\%), Raillietina echinobothrida (6\%), and Choanotaenia infundibulum (8\%); lungs: S. trachea $(16 \%)[14]$.

Among parasitic infections of the birds, Choanotaenia spp. infects the posterior part of the small intestine of poultries and turkeys, and Raillietina spp. can involve the posterior part of the small intestine of the poultries, guinea fowls, turkeys, pheasants, and quails. These worm parasites have also been reported from different types of birds in Iran $[14,15]$. In addition, Ascaridia spp. and S. trachea have been reported in the domestic and wild poultry of Iran [14-18]. However, the most studies focused on intestinal, blood parasites, and recently avian schistosomes in native and not often in migratory bird species in Iran [14-21].

In this study, 11 samples were infected with Taenia spp. and Toxocara spp.; both of which have the potential risk for infecting the human population. Given that swallows usually nest in residential places such as homes and hospitals, and because of the transmission of zoonotic parasitic infections by these birds, it is believed that swallows can pose a serious threat to human health and environment [22].

Furthermore, a Moniezia spp. (a parasite of ruminants) and Toxocara spp. (a parasite of dogs and cats) eggs were found in the swallow excreta. Swallows use wood and leaves to build their nests, which are likely to be infected to ruminants' and carnivores fecal materials. It seems that the swallowing of the feces by these birds has caused infection by Moniezia and Toxocara spp. parasites. Consequently, those harbored these parasites considered as pseudo host, because the parasites transiently exist within the alimentary canal.
Our data demonstrate that fecal samples of swallows may harbor different species of parasites (mainly A. galli, Taenia spp., and Toxocara spp.) and may be capable of distributing these parasites in the private and public environments. Considering the fact that migratory swallows are common in Iran and having a coexisting relationship with humans in our country; therefore, it needs an awareness of the general population to prevent transmission of the parasitic infections by barn swallow in the region.

\section{Conclusion}

Given that the migratory swallows are considered as a holy bird in Iran and build their nests in closeness to human homes and around the public places, for example, hospitals and streets, these birds might be as a latent and hazardous source for distribution of zoonotic parasitic infections. As a whole, our results also highlight further studies on the distribution of gastrointestinal parasites among swallow excreta, especially zoonotic ones and determination true burden of these in other parts of Iran as well as the worldwide.

\section{Authors' Contributions}

MF designed all steps of the study, RB and SA collected the samples, $\mathrm{ZH}$ and TNC examined the collected samples, and RS wrote the manuscript draft. All authors read, revised, and approved the final draft.

\section{Acknowledgments}

The authors are thankful to state their thanks to Vice Chancellor for Research and Technology and also Student Research Committee of Mazandaran University of Medical Sciences for funding (grant number: 195-96). 


\section{Competing Interests} interests.

The authors declare that they have no competing

\section{References}

1. Turner, A. (2004) Family Hirundinidae (swallows and martins). Handbook of the Birds of the World. Lynx Edicions, Barcelona, Spain.

2. Moller, A.P. (2001) The effect of dairy farming on Barn swallow Hirundo rustica abundance, distribution and reproduction. J. Appl. Ecol., 38(2): 378-389.

3. Brown, C.R. and Bomberger, M. (1999) Barn swallow (Hirundo rustica). In: Poole A, editor. The Birds of North America Online. Cornell Lab of Ornithology, Ithaca. Available from: http://www.bna.birds.cornell.edu/bna/species/452/articles/introduction. Last accessed on 12-09-2016.

4. Available from: http://www.en.wikipedia.org/wiki/Swallow. Last accessed on 12-09-2016.

5. Qi, M., Wang, R., Ning, C., Li, X., Zhang, L., Jian, F., Sun, Y. and Xiao, L. (2011) Cryptosporidium spp. in pet birds: Genetic diversity and potential public health significance. Exp. Parasitol., 128(4): 336-40.

6. Cafarchia, C., Romito, D., Iatta, R., Camarda, A., Montagna, M. and Otranto, D. (2006) Role of birds of prey as carriers and spreaders of Cryptococcus neoformans and other zoonotic yeasts. Med. Myco., 44(6): 485-492.

7. Park, S.I. and Shin, S.S. (2010) Concurrent Capillaria and Heterakis infections in zoo rock partridges, Alectoris graeca. Korean J. Parasitol., 48(3): 253-257.

8. Narayanan, P.M., Karunakaran, S., Ravindran, R., Gopalan, A.K.K., Chandrasekhar, L., Sukumaran, S.I. and Kalarikkal, D.C. (2014) Occurrence of fatal syngamosis in emu birds of Kerala. J. Parasit. Dis., 38(2): 241-243.

9. Hedayati, M.T., Mayahi, S., Fakhar, M., Shokohi, T. and Majidi, M. (2011) Cryptococcus neoformans isolation from swallow (Hirundo rustica) excreta in Iran. Rev. Inst. Med. Trop. Sao. Paulo, 53(3): 125-127.

10. Mahjouri, E. (2013) Historical Geography of Mazandaran Province. Geographical Organization Press, Tehran, Iran.

11. Garcia, L.S. and Bruckner, D.A. (2016) Diagnostic Medical
Parasitology. ASM Press, Washington, DC.

12. Soulsby, E.J.L. (1984) Helminths, Arthropods and Protozoa of Domesticated Animals. Bailliere Tindall Publishing, UK.

13. Atkinson, C.T., Thomas, N.J. and Hunter, D.B. (2008) Parasitic Diseases of Wild Birds. Blackwell, USA.

14. Eslami, A., Ghaemi, P. and Rahbari, S. (2009) Parasitic infections of free-range chickens from Golestan Province, Iran. Iran. J. Parasitol., 4(3): 10-4.

15. Mamashly, M., Rqnjbar-Bahadori, S.H., Safdari, A. and Aghaebrahimi-Samani, R. (2010) Study on parasitic infections of native poultry in Golestan Province. Comp. Pathobiol., 7(1): 189-192.

16. Halajian, A., Eslami, A., Mobedi, I., Amin, O., Mariaux, J., Mansoori, J. and Tavakol, S. (2011) Gastrointestinal helminths of magpies (Pica Pica), rooks (Corvus frugilegus) and carrion crows (Corvus corone) in Mazandaran Province, North of Iran. Iran. J. Parasitol., 6(2): 38-44.

17. Badparva, E., Ezatpour, B., Azami, M. and Badparva, M. (2015) First report of birds infection by intestinal parasites in Khorramabad, West Iran. J. Parasit. Dis., 39(4): 720-724.

18. Bahadory, S.H.R., Ramezani, A., Babazadeh, D., Falah, S. and Ghavami, S. (2014) Evaluation of gastrointestinal helminths of native turkeys in Amol Iran. J. Poult. Res., 4(4): 86-88.

19. Fakhar, M., Kalani, H., Rahimi-Esboei, B. and Armat, S. (2013) Hemoprotozoa in free-ranging birds from rural areas of Mazandaran Province, northern Iran. Comp. Clin. Pathol., 22(3): 509-512.

20. Nourani, L., Aliabadian, M., Dinparast-Djadid, N. and Mirshamsi, O. (2017) New host records for Haemoproteus Spp. (Apicomplexa: Haemosporidiasina) in Passeriformes from North-West of Iran. J. Arthropod. Borne. Dis., 11(2): 236-241.

21. Fakhar, M., Ghobaditara, M., Brant, S.V., Karamian, M., Gohardehi, S. and Bastani, R. (2016) Phylogenetic analysis of nasal avian schistosomes (Trichobilharzia) from aquatic birds in Mazandaran Province, Northern Iran. Parasitol. Int., 65(2): 151-158.

22. Moller, A.P. (1994) Parasites as an environmental component of reproduction in birds as exemplified by the swallow Hirundo rustica. Ardea, 82: 161-172. 